\title{
DIVERSITY OF MICROCYSTINS AND NON-MICROCYSTIN-PRODUCING Microcystics POPULATION IN THE DAU TIENG RESERVOIR, VIETNAM
}

\author{
Pham Thanh Luu ${ }^{1,2 *}$ \\ ${ }^{1}$ Institute of Tropical Biology, VAST \\ ${ }^{2}$ Graduate University of Science and Technology, VAST
}

\begin{abstract}
In this study, a $16 \mathrm{~S}$ rDNA clone library was used to evaluate the diversity of potential microcystin producing cyanobacteria and polymerase chain reaction (PCR) was used to analyze the diversity of this population based on the presence of the mcyD gene in samples collected during a bloom season. The results revealed that Microcystis genera from the Dau Tieng reservoir (DTR) contained several genotypes. The isolated Microcystis strains from the DTR were found to consist both toxic and non-toxic species within species and population. In total 35 strains accounted for 58\% were found to produce a mixture of microcystins (MCs). All samples of cyanobacterial blooms in the DTR contained high amount of MCs which could pose health risk to aquatic systems and local people.
\end{abstract}

Keywords: Microcystis, 16S rDNA, diversity, phylogenetic analyses, reservoir.

Citation: Pham Thanh Luu, 2018. Diversity of microcystins and non-microcystin-producing microcystis population in the Dau Tieng reservoir, Vietnam. Academia Journal of Biology, 40(4): 57-66. https://doi.org/10.15625/2615-9023/v40n4.10265.

*Corresponding author email: thanhluupham@gmail.com

Received 25 June 2017, accepted December 2018

\section{INTRODUCTION}

Cyanobacteria are notorious for their ability to produce a variety of toxic secondary metabolites named cyanotoxins, which can be especially toxic to aquatic animal and human during cyanobacterial blooms (Sivonen, 1996). Among cyanotoxins, microcystins (MCs) are the most prominent cyanobacterial hepatotoxins in inland waters (Chorus Bartram, 1999). The MCs are cyclic heptapeptide hepatotoxins synthesized nonribosomally by a multifunctional enzyme complex that includes peptide synthetase (NRPS) and polyketide synthase (PKS) modules. Both NRPS and PKS are encoded by the microcystin synthetase gene ( $m c y)$ cluster, which contains $55 \mathrm{~kb}$ of DNA. The $m c y$ gene has been characterized in many cyanobacterial genera such as Microcystis, Anabaena and Planktothrix (Christiansen et al., 2003; Rouhiainen et al., 2004; Tillett et al., 2000). To date, more than 100 structural variants of MCs have been identified from cyanobacterial blooms and isolated strains worldwide, in which MC-LR, -RR and -YR are the three most common types reported in natural waters (Puddick et al., 2014).

Microcystins are mainly produced by several genera of cyanobacteria including Microcystis, Planktothrix and Anabaena (Pham et al., 2015). Thereinto, Microcystis sp. is the most common bloom-forming 
cyanobacteria worldwide. Microcystis sp. has been reported to be the bloom-forming species in Vietnamese waters (Duong et al., 2014; Dao et al., 2016; Pham et al., 2015). Multiple species have been recorded in this genera based on morphological taxonomy. Moreover, genotypic diversity and toxin production of these species has been characterized in temperate regions (Kurmayer et al., 2003; Otsuka et al., 1999; Vaitomaa et al., 2003). However, little is known about the diversity of Microcystis, especially on their gentic diversity in tropical region. Thus, knowledge of the diversity and distribution of Microcystis species in tropical areas is important to understand the dynamics of Microcystis blooms.

Morphological methods have traditionally been used to monitor and characterize cyanobacteria. However, blooms of cyanobacteria usually consist of toxic and non-toxic strains (Kardinaal et al., 2007; Neumann et al., 2000). Traditional morphological methods cannot be used as the basis for differentiation of toxic and non-toxic strains because many strains of cyanobacteria appear to be identical under the microscope. Therefore, the current taxonomy of Microcystis depending upon morphological characteristics must be reviewed by means of molecular techniques. The presence or absence of the $m c y$ gene cluster has been widely used as a means for distinguishing between two genotypes and recently has been used to reveal the presence of MC-producing cyanobacteria in both environmental samples and axenic cultures (Bittencourt-Oliveira, 2003; Hisbergues et al., 2003; Hotto et al., 2005). In addition, phylogenetic analysis based on $16 \mathrm{~S}$ rDNA is a commonly used method for microbiologic taxonomy because it was considered as one of the most valid criteria for determining relationships among closely related organisms (Otsuka et al., 1999).
Studies evaluating the diversity and dynamics of MCs producing cyanobacteria based on the mcy gene and 16S rDNA sequence have recently been conducted in eutrophic lakes in Japan (Yoshida et al., 2007), Finland (Vaitomaa et al., 2003), Germany (Kurmayer et al., 2003), Canada and the United States (Rinta-Kanto et al., 2006) during the bloom season. The results of these studies described the diversity of toxic and non-toxic communities in those aquatic environments. However, few studies have been conducted to elucidate the problems associated with MC-producing cyanobacteria in hypertrophic lakes in tropical areas such as Vietnam, even though they represent a serious environmental problem in many drinking water resources (Pham et al., 2015).

The objective of this study was to elucidate the bloom dynamics and community composition of microcystin-producing and non-microcystin-producing of the Microcystis genotypes in Dau Tieng reservoir. Traditional methods and molecular techniques using the $16 \mathrm{~S}$ rDNA and the $m c y$ genes were employed to understand the phylogeny of Microcystis species.

\section{MATERIALS AND METHODS}

\section{Sample collection}

Sampling was carried out monthly in the area where Microcystis scums occurred in Dau Tieng resevoiz from May to October 2016. The sampling sites were located near Phuoc Ninh commune, Duong Minh Chau district, Tay Ninh province where cyanobacterial blooms usually lasted 4-5 months a year (Pham et al., 2015). Cyanobacteria and water samples were collected at a depth of $30 \mathrm{~cm}$ below the lake surface into 2-L sterile plastic bottles. The samples were then stored in a cooler at $4^{\circ} \mathrm{C}$ and transported to the laboratory for analysis. The water samples $(10-50 \mathrm{~mL})$ were filtered on GF/C fiber filters (Whatman, Enlangd), and the filters containing microbes were used for MCs extraction (Pham et al., 2015). 
Cyanobacterial samples for qualitative analysis were collected with a conical plankton net with a mesh size of $25 \mu \mathrm{m}$. Samples for quantitative analysis of cyanobacteria were collected using $500 \mathrm{~mL}$ of surface water fixed with formaline to $2 \%$.

\section{Isolation and cultivation}

Living and Lugol-fixed cyanobacterial species were morphologically identified under a light microscope (Olympus BX51) equipped with a digital camera and DP71 software (Olympus, Tokyo, Japan). Taxonomic classification was based on the system described by Komárek Anagnostidis (1989, 1999, 2005). Cyanobacteria were isolated by micropipetting and washing. A single cyanobacterial colony of Microcystis was isolated by micropipetting, washed, and transferred into cyanobacterial growth medium (Belcher and Swale, 1988). Cyanobacteria were grown in Z8 medium (Kotai, 1972). All cultures were grown on a 12:12 light:dark cycle at a temperature of $28^{\circ} \mathrm{C}$ under light conditions provided by $40-\mathrm{W}$ fluorescent lamps, which provided an approximate luminic intensity of $20 \mu \mathrm{mol}$ photons $/ \mathrm{m}^{2} \mathrm{~s}$. Biomasses of cyanobacterial cultures were harvested onto $\mathrm{GF} / \mathrm{C}$ glass fiber filters (Whatman, Kent, England) dry at $45^{\circ} \mathrm{C}$ overnight and kept at $\left(-20^{\circ} \mathrm{C}\right.$ until further processes.

\section{DNA extraction}

Total genomic DNA was extracted from cyanobacterial retained on filters following the methods described previously by Hisbergues et al. (2003) with minor modifications. Briefly, the filters contained cyanobacterial cells were suspended in TE buffer $(50 \mathrm{mM}$ Tris/HCl, $40 \mathrm{mM}$ EDTA, $\mathrm{pH}$ 8.0). An aliquot of $30 \mu \mathrm{L}$ of $10 \%$ SDS (sodium dodecyl sulfate) and proteinase $\mathrm{K}$ (final concentration: $100 \mu \mathrm{g} / \mathrm{mL}$ in $0.5 \%$ SDS) was then added and incubated for $60 \mathrm{~min}$ at $37^{\circ} \mathrm{C}$. Then $5 \mathrm{M} \quad \mathrm{NaCl}(100 \mu \mathrm{L})$ and $\mathrm{CTAB} / \mathrm{NaCl}$ solution $(10 \% \mathrm{CTAB}$ in $0.7 \mathrm{M}$ $\mathrm{NaCl})(80 \mu \mathrm{L})$ were added, and the samples were incubated for $10 \mathrm{~min}$ at $65^{\circ} \mathrm{C}$. DNA was then extracted twice with phenol:chloroform:isoamyl alcohol (25:24:1 $\mathrm{v} / \mathrm{v})$. After centrifugation for $5 \mathrm{~min}$ at $6000 \times$ $g$ at $4{ }^{\circ} \mathrm{C}$, the supernatant was collected and transferred to a fresh tube. The DNA was then rinsed with $1 \mathrm{~mL}$ of $70 \%$ ethanol and dried under vacuum. The final DNA sample was rehydrated in $20 \mu \mathrm{L}$ of $1 \times$ TE buffer $(10 \mathrm{mM}$ Tris and $1 \mathrm{mM}$ EDTA [pH 8.0]).

\section{PCR amplification and 16S rDNA sequence}

To detect the presence of cyanobacterial DNA, the CYA primer pair (Urbach et al., 1992) was used to amplify a $1200 \mathrm{bp}$ fragment of the 16s rDNA gene common to all cyanobacteria. To detect the $m c y$ gen in toxic Microcystis, the polyketide synthase fragment (mcyD, $297 \mathrm{bp}$ ) was amplified using primer pair $m c y D-F 2 / m c y D-\mathrm{R} 2$ (Kaebernick et al., 2000). For each sample, two separate PCRs were conducted. All PCR reactions were prepared in a volume of $20 \mu \mathrm{L}$ containing 2 $\mu \mathrm{L}$ of $10 \times$ Ex-Taq Buffer, $200 \mu \mathrm{M}$ of each dNTP, $0.5 \mu \mathrm{L}$ of each primer $(10 \mu \mathrm{M}), 0.5 \mathrm{U}$ of Ex-Taq polymerase and $20 \mathrm{ng}$ of template DNA. Amplification was performed in a Thermal Cycler (Applied Biosystems, Foster City, California, USA) follow the condition: initial denaturation at $95^{\circ} \mathrm{C}$ for $10 \mathrm{~min}, 35$ cycles $\left[94^{\circ} \mathrm{C} / 1 \mathrm{~min}, 54^{\circ} \mathrm{C} / 1 \mathrm{~min}, 72^{\circ} \mathrm{C} / 1.5\right.$ min] and a final extension step at $72^{\circ} \mathrm{C}$ for 10 min. PCR products were examined on $1.5 \%$ $(\mathrm{w} / \mathrm{v})$ agarose gels stained with ethidium bromide and photographed under UV transillumination.

The PCR product was used as DNA template for the $16 \mathrm{~S}$ rDNA clone library analysis. The PCR products were cloned into a pCR2 II vector (Invitro-gen, Carlsbad, CA, USA) according to the manufacturer's instructions. The sequencing was carried out on an ABI PRIS M1 3100-Avant Genetic Analyzer (Applied Biosystems, Foster City, CA, USA) with an ABI PRIS M1 BigDye Terminator v3.1 Cycle Sequencing Kit following the manufacturer's directions (Applied Biosystems, Foster City, CA, USA). 
The sequence alignment datas were obtained using CLUSTAL X, version 1.81.

\section{Alignment and phylogenetic analyses}

Individual 16S rDNA sequences were queried against GenBank by BLAST and BLASTX searches and analyzed at both the nucleotide and amino acid levels. The 16S rDNA sequences were multiple-aligned using CLUSTAL X, version 1.81. Genetic distances were calculated using the method of neighbor joining with p-distance as implemented in MEGA 5 program package (Tamura et al., 2011). Similar phylogenetic trees were also created by maximum parsimony and minimum-evolution analyses. Only bootstrap percentages above 50 (for 1000 iterations) were shown at the branch nodes of phylogenetic distance trees.

\section{Microcystins extraction and analysis}

Intracellular MCs extraction and analysis were conducted as described by Pham et al. (2015) with minor modifications. Briefly, MCs from the dried filters were first extracted in $4 \mathrm{~mL}$ of $100 \%$ methanol $(\mathrm{MeOH})$ followed by two 60 -min extractions in $3 \mathrm{~mL}$ of $75 \%$ (vol/vol) aqueous $\mathrm{MeOH}$. Each extraction step was followed by sonication for $3 \mathrm{~min}$ and centrifugation $\left(1800 \times \mathrm{g}, 30 \mathrm{~min}, 4^{\circ} \mathrm{C}\right)$. The supernatants of all extractions from each sample were pooled, dried at room temperature, re-dissolved in $0.5 \mathrm{~mL} \mathrm{MeOH}$ $(100 \%)$ and centrifuged at $4000 \times \mathrm{g}$ for $5 \mathrm{~min}$. The supernatant was passed through a Minisart RC4 filter membrane $(0.2 \mu \mathrm{m}$ pore size, Sartorius Stedim Biotech, Göttingen, Germany), and kept at $-20^{\circ} \mathrm{C}$ prior to reversephase HPLC analysis.

A reverse-phase HPLC with UV-visible photodiode array (PDA) detector (Dionex UltiMate 3000, Thermo Scientific, Waltham, MA USA) was equipped with a silica-based, reverse-phase $\mathrm{C} 18$ column $\left(\right.$ Acclaim $^{\mathrm{M}} 120$ C18 $5 \mu \mathrm{m}, 4.6 \times 150 \mathrm{~mm}$, Waltham, MA USA) and maintained at $40^{\circ} \mathrm{C}$. The samples were separated with a mobile phase consisting of methanol: $0.05 \mathrm{M}$ phosphate buffer $(\mathrm{pH}$ $2.5 ; 50: 50 \mathrm{v} / \mathrm{v}$ ) at a flow rate of $0.58 \mathrm{~mL} / \mathrm{min}$. Microcystin congeners were detected by UV detection at $238 \mathrm{~nm}$ and identified on the basis of both their retention time and characteristic UV spectra. Microcystins (MC-LR, MC-RR, and MC-YR) purchased from Wako Pure Chemical Industries, Ltd. (Chuoku, Osaka, Japan), were used as standards. The HPLC system had a detection limit of $0.12 \mu \mathrm{g} / \mathrm{L}$.

\section{RESULTS}

\section{Isolation and morphological characteristics}

Microscopic examination of the cyanobacterial bloom samples revealed the dominance of Microcystis (mainly $M$. aeruginosa) and the less frequent occurrence of other genera (Dolichospermum, Arthrospira, Planktothrix and Cylindrospermopsis). Identification of individual Microcystis colonies revealed the occurrence of six species: $M$. aeruginosa, $M$. botrys, $M$. novacekii, $M$. flos-aquae, $M$. wesenbergii and $M$. panniformis (Fig. 1). A total of 60 Microcystis strains were isolated from the cyanobacterial and maintained in cultures.

\section{Molecular characterization of the Microcystis strains}

In total 60 Microystis strains have been isolated and maintained under laboratory conditions. All isolated strains were examined by the $16 \mathrm{~S}$ rDNA and the $m c y D$ fragments. The 16S rDNA fragments presented in all strains confirmed that all strains examined were cyanobacteria (Fig. 2a). The use of the $m c y D-\mathrm{F} 2 / m c y D-\mathrm{R} 2$ primers in the PCR yielded $300 \mathrm{bp}$ amplicons of the different studied strains, indicating the presence of $m c y D$ genes in these strains. In total, the $m c y D$ region was detected in 38 of the 60 strains (Fig. 2b). This amplicon was obtained from Microcystis isolates, which correspond to potential toxigenic strains (toxic producing strains), since they presented the mcy genes. 
The strains Ma-6 corresponding to the cyanobacterium $M$. aeruginosa, Mb-1, Mb-2, Mb-3 corresponding to the cyanobacterium $M$. botrys, Mw-1, Mw-2, Mw-3 corresponding to the cyanobacterium $M$. wesenbergii and Mf-2 corresponding to the cyanobacterium $M$. flosaquae could not be amplified despite the fact that the reaction was repeated several time. These strains corresponded to non-toxin producing strains (Fig. 2b).

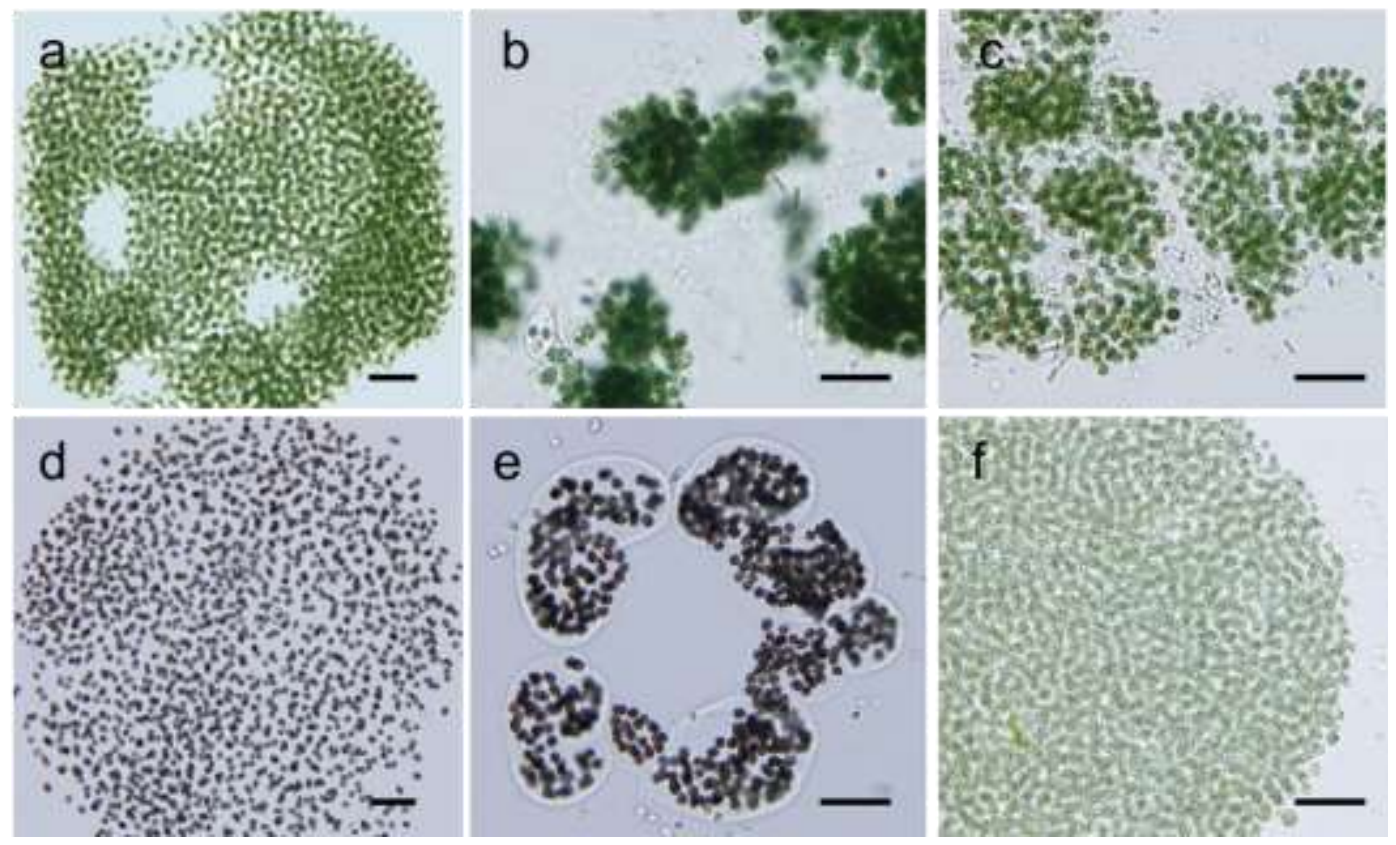

Figure 1. Microcystis strains under microscope: (a) Microcystis aeruginosa; (b) M. botrys; (c) M. novacekii; (d) M. flos-aquae; (e) M. wesenbergii; (f) M. panniformis. Scale bar: $20 \mu \mathrm{m}$
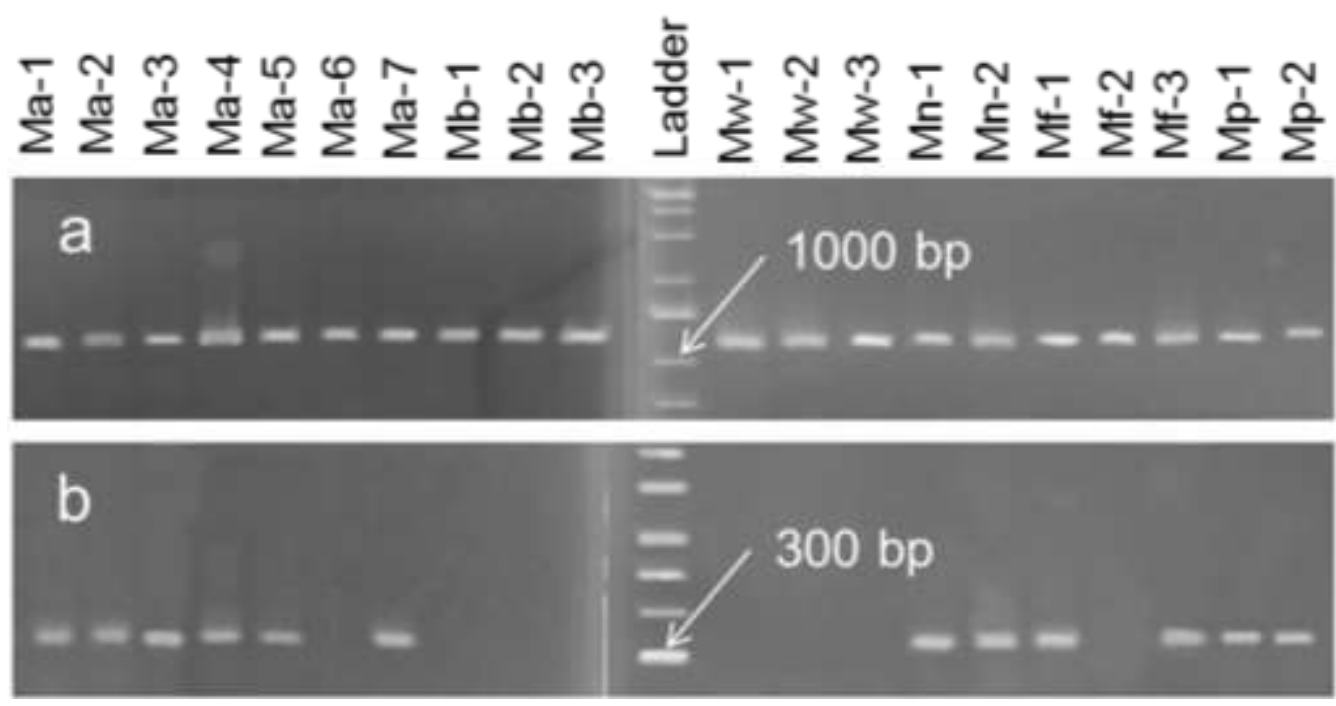

Figure 2. Ethidium bromide stained agarose electrophoresis gels showing PCR amplification products for selected strains. Fig. 2a. 16S DNA amplification products. Fig. 2b. mcyD amplification products. Molecular marker: PHY ladder; other lanes represent the different strains in the study (See list in Table 1) 
Quantification of microcystins with HPLC

Results of HPLC analysis for $3 \mathrm{MCs}$ variants MC-RR, MC-LR and MC-YR indicated that 35/60 cultured strains (58\%) contained MCs. Almost all strains positive with the $m c y D$ can produce MCs (except 3 strains Mn-9, Mf-7 and Mp-4). MCs producing strains were classified into the $M$. aeruginosa, M. novacekii, M. flos-aquae and $M$. panniformis while non-MC producing strains were belonging to $M$. botrys and $M$. wesenbergii and some strains of $M$. aeruginosa, M. novacekii, M. flos-aquae and
M. panniformis. The total concentration of MCs from toxic isolated strains ranged from 11.6 to $1218.6 \mu \mathrm{g} / \mathrm{g}$ dry weight (DW) (Table 1). The MCs content of these strains was quite variable. The minimum content of MCs was found in the strain Ma-1 (11.6 $\mu \mathrm{g} / \mathrm{g} \mathrm{DW})$ and the maximum in Ma-7 (891.4 $\mu \mathrm{g} / \mathrm{g} \mathrm{DW})$.

Four bloom samples collected from May to September, 2016 contained three MCs, MC-LR, MC-RR and MC-YR. The total concentration of all MCs in those samples ranged from 568 to $875 \mu \mathrm{g} / \mathrm{g}$ DW (Table 1).

Table 1. List of isolated strains with amplification of the $m c y D$ region and total microcystin content

\begin{tabular}{|c|c|c|c|c|}
\hline No. & Strain & Taxonomic identification & $m c y D$ & $\mathrm{MC}(\mu \mathrm{g} / \mathrm{g} \mathrm{DW})$ \\
\hline 1 & Ma-1 & M. aeruginosa & + & 198.4 \\
\hline 2 & Ma-2 & M. aeruginosa & + & 11.6 \\
\hline 3 & Ma-5 & M. aeruginosa & + & 768.5 \\
\hline 4 & Ma-6 & M. aeruginosa & - & UDL \\
\hline 5 & Ma-7 & M. aeruginosa & + & 891.4 \\
\hline 6 & $\mathrm{Mb}-2$ & M. botrys & - & UDL \\
\hline 7 & Mn-2 & M. novacekii & + & 131.2 \\
\hline 8 & $\mathrm{Mn}-4$ & M. novacekii & + & 348.9 \\
\hline 9 & Mn-9 & M. novacekii & + & UDL \\
\hline 10 & Mf-1 & M. flos-aquae & + & 581.6 \\
\hline 11 & Mf-7 & M. flos-aquae & + & UDL \\
\hline 12 & $\mathrm{Mp}-1$ & M. panniformis & + & 678.3 \\
\hline 13 & $\mathrm{Mp}-4$ & M. panniformis & + & UDL \\
\hline 14 & Mw-2 & M. wesenbergii & - & UDL \\
\hline 15 & Bloom in May 2016 & \multirow{4}{*}{ Natural bloom biomass } & & 568.3 \\
\hline 16 & Bloom in Jul 2016 & & & 765.8 \\
\hline 17 & Bloom in Aug 2016 & & & 874.6 \\
\hline 18 & Bloom in Sep 2016 & & & 758.2 \\
\hline
\end{tabular}

UDL: under detection limit

\section{Phylogenetic tree based on 16S rDNA sequences}

The amino acid sequences deduced from the amplified 16s rDNA gen fragment were used to construct a phylogenetic tree (Fig. 3). All of the sequences that appeared in the phylogenetic tree were affiliated with Microcystis-like cyanobacteria, whereas MCproducing Microcystis-like and non-toxic
Microcystis-like cyanobacteria could not differentiate by using the $16 \mathrm{~S}$ rDNA sequences.

Constructed phylogenetic trees revealed that all the Microcystis strains formed two defined cluster. Cluster I includes most of the strains of $M$. aeruginosa from the DTR and some of M. novacekii, M. flos-aquae and M. panniformis and M. aeruginosa (NIES-1099) from Japan. However all strains not belonging 
to $M$. aeruginosa from the resevoiz form a sub-cluster. Other strains formed cluster II that consists of other Microcystis genotype inculuding $M$. fos-aquae, $M$. botrys, $M$. novacekii and $M$. wesenbergii and $M$. viridis (NIES-102) from Japan.

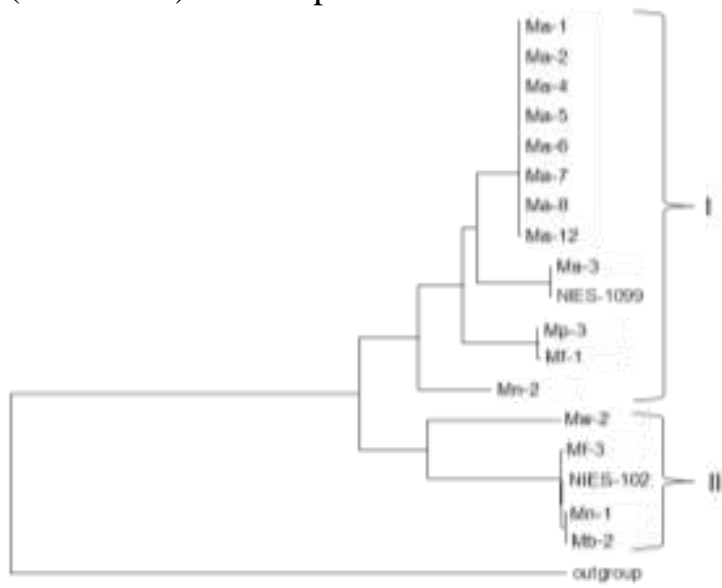

Figure 3. Phylogenetic tree based on $16 \mathrm{~S}$ rDNA sequences showing the relationships between cyanobacteria strains of Microcystis. Outgroups were Aquifex aeolicus. An alignment of 1170 nucleotides was used

\section{DISCUSSION}

Cyanobacterial blooms caused by Microcystis were observed in the DTR during dry and wet seasons of the year. The DTR is located in the tropical zone, which has a warm climate. The warm climate combining with its hypertrophic status would likely favor the recruitment of cyanobacteria and the extended duration of cyanobacterial blooms, which may start in April and persist until October. The results of a previous study revealed that Microcystis, Anabaena and Planktothrix coexisted in the DTR (Pham et al., 2015). Microcystis was the main MC-producing cyanobacteria present in the reservoir throughout the year (Pham et al., 2015). Toxic cyanobacteria may not produce MC during times of low growth, but those containing the mcy genotypes were able to survive throughout the year (Ye et al., 2009). The traditional PCR technique can not quantify the toxic and non-toxic genotypes. To gain a better understanding of the proportion of toxic and non-toxic Microcystis population in the resevoiz, quantification of the potential MCproducing cyanobacterial population by realtime PCR was highly recommended.

PCR-based detection of genes involved in the synthesis of MCs is a reliable techniques and has been successfully applied for determination of toxic and non-toxic cyanobacteria worldwide (BittencourtOliveira et al., 2012; Hisbergues et al., 2003; Rinta-Kanto et al., 2006; Yoshida et al., 2007). Previous study have showed that the $m c y D$ which encodes for parts of both the $\beta$ ketoacyl synthase and the acyltransferase domains (Pham et al., 2015) is one of the best molecular markers for determination of potential toxicity of cyanobacteria. In this study, the applification of the $m c y D$ showed again reliable results to distingiush toxic and non-toxic Microcystis. Therefore, the results of this study recommend to use this DNA fragment for the determination of toxic genetics of Microcystis in other Vietnamese waters. In general, toxic strains contain $m c y$ genes, therefore they can amplify the mcyD gen fragment. However, some strains showed positive with $m c y D$ but MCs proteins could not detected by HPLC. Probably, these strains produce a small amount of MCs which is under detection limit of the present HPLC system. Other more sensitive techniques for detection of MCs such as ELISA or phosphatase assay should be performed.

The analysis of the 16S rDNA of Microcystis strains from the resevoiz and of the reference strains from Genbank showed a separation between two Clusters. The phylogenetic tree showed that cluster I includes most of the strains of $M$. aeruginosa from the resevoiz, in addition to strains of $\mathrm{M}$. aeruginosa from (sub)-tropical regions like 
Japan. Cluster II, on the other hand, consists of strains of other Microcystis genotypes including $M$. fos-aquae, $M$. botrys, $M$. novacekii and $M$. wesenbergii and $M$. viridis (NIES-102) from Japan. And this group, on the basis of the sequences included in this study, there seems to be the cosmopolitan species as noted by Bittencourt-Oliveira et al. (2001), the Microcystis sp. genotypes most likely represent a series of related populations sharing a common phylogenetic history. Phylogenetic analyses based on DNA sequences are an useful tool for understanding the diversity of cyanobacteria when combined with traditional methods based on morphological and physiological characteristics.

In Vietnam, there are many artificial lakes used for water supplies and recreational activities in which cyanobacterial bloom formation associated with MCs production is frequenly increased due to the high degree of eutrophication (Dao et al., 2016; Duong 2014; Hummert et al., 2001; Pham et al., 2015; 2017). MCs concentration in water exceeding the WHO guideline value of $1.0 \mu \mathrm{g} / \mathrm{L}$ have also been reported in the Tri An and DTR (Dao et al., 2016; Pham et al., 2015). This deserves special attention given the potential risk to human health and animal sanitation posed by blooms, since toxicity has been documented to $75 \%$ of blooms cases (Chorus and Batram, 1999). Among the toxic species, $M$. aeruginosa is one of the most common and widespread bloom-forming cyanobacteria in freshwater environments. This species was also reported the bloom-forming in many Vietnamese water bodies (Dao et al., 2016; Duong 2014; Hummert et al., 2001; Pham et al., 2017). Results of this study showed that $M$. aeruginosa was the bloom-forming in the DTR. Toxic Microcystis genotypes including M. aeruginosa, M. novacekii, $M$. flos-aquae and $M$. panniformis were the main toxin producers. All samples of cyanobacterial blooms in the DTR contained high amount of
MCs which could pose health risk to aquatic systems and local people. Hence, further investigations are recommended to elucidate the cause and minimize of these blooms.

\section{CONCLUSION}

The combined use of HPLC and PCR allowed us to identify the primary putative MC-producing cyanobacteria in the resevoiz. The molecular detection of potential MCproducer was found to be very sensitive, and could be used to assist in direct chemical measurements of the toxins. These PCR-based techniques could be utilized in monitoring and early warning programs for the detection of toxic blooms in lakes and reservoirs. In Vietnam, some water bodies used for drinking purpose experience with cyanobacterial blooms, continuous evaluation and surveillance programs must be implemented to be able to evidence the presence of cyanobacteria with toxigenic potential and mitigate these toxic effects.

Acknowledgements: This research was founded by the Vietnam National Foundation for Science and Technology Development (NAFOSTED) under grant number "106.042018.314”.

\section{REFERENCES}

Belcher H., Swale E., 1988. Culturing algae-A guide for schools and colleges, The Ferry House, UK, pp. 80.

Bittencourt-Oliveira D. C. M., De Oliveira M. C., Bolch C. J. S., 2001. Genetic variability of brazilian strains of the microcystis aeruginosa complex (cyanobacteria/cyanophyceae) using the phycocyanin intergenic spacer and flanking regions (cpcBA). J. Phycol., 37(5): 810-818.

Bittencourt-Oliveira D. C. M., 2003. Detection of potential microcystinproducing cyanobacteria in Brazilian 
Diversity of microcystins and non-microcystin-producing

reservoirs with a mcyB molecular marker. Harmful Algae, 2(1): 51-60.

Bittencourt-Oliveira D. C. M., Piccin-Santos V., Gouvea-Barros S., 2012. Microcystinproducing genotypes from cyanobacteria in Brazilian reservoirs. Environ. Toxicol., 27(8): 461-471.

Chorus I., Bartram J., 1999. Toxic cyanobacteria in water: A guide to their public health consequences, monitoring and management. London: E \& FN Spon, pp. 415.

Christiansen G., Fastner J., Erhard M., Borner T., Dittmann E., 2003. Microcystin biosynthesis in Planktothrix: genes, evolution, and manipulation. J. Bacteriol., 185(2): 564-572.

Dao T. -S., Nimptsch J., Wiegand C., 2016. Dynamics of cyanobacteria and cyanobacterial toxins and their correlation with environmental parameters in Tri An Reservoir, Vietnam. J. Water Health, 14: 669-712.

Duong T. T., Jähnichen S., Le T., Ho C., Hoang T., Nguyen T., Vu T., Dang D., 2014. The occurrence of cyanobacteria and microcystins in the Hoan Kiem Lake and the Nui Coc reservoir (North Vietnam). Environ. Earth Sci., 71(5): 2419-2427.

Hisbergues M., Christiansen G., Rouhiainen L., Sivonen K., Börner T., 2003. PCRbased identification of microcystinproducing genotypes of different cyanobacterial genera. Arch. Microbiol., 180(6): 402-410.

Hotto A., Satchwell M., Boyer G., 2005. Seasonal production and molecular characterization of microcystins in Oneida Lake, New York, USA. Environ. Toxicol., 20(3): 243-248.

Hummert C., Dahlmann J., Reinhardt K., Dang H., Dang D., Luckas B., 2001. Liquid chromatography-mass spectrometry identification of microcystins in Microcystis aeruginosa strain from lake Thanh Cong, Hanoi, Vietnam. Chromatographia, 54(9): 569575.

Kaebernick M., Neilan B. A., Borner T., Dittmann E., 2000. Light and the transcriptional response of the microcystin biosynthesis gene cluster. Appl. Environ. Microbiol., 66(8): 3387-3392.

Kardinaal W. E. A., Janse I., Agterveld M. K.V., Meima M., Snoek J., Mur L. R., Huisman J., Zwart G., Visser P. M., 2007. Microcystis genotype succession in relation to microcystin concentrations in freshwater lakes. Aquat. Microb. Ecol., 48(1): 1-12.

Komárek J. and Anagnostidis K., 1989. Modern approach to the classification system of Cyanophytes. 4 - Nostocales. Arch. Hydrobiol. Suppl. 82(3): 247-345.

Komárek J., Anagnostidis K., 1999. Cyanoprokaryota 1. Teil: Chroococcales, pp 548.

Komárek J., Anagnostidis K., 2005. Cyanoprokaryota 1. Teil: Oscillatoriales. (19/2), pp. 759.

Kotai J., 1972. Instructions for preparation of modified nutrient solution Z8 for algae. Norwegian Institute for Water research Oslo B-11/69, pp. 5.

Kurmayer R., Christiansen G., Chorus I., 2003. The abundance of microcystinproducing genotypes correlates positively with colony size in Microcystis sp. and determines its microcystin net production in Lake Wannsee. Appl. Environ. Microbiol, 69(2): 787-795.

Neumann U., Campos V., Cantarero S., Urrutia H., Heinze R., Weckesser J., Erhard M., 2000. Co-occurrence of nontoxic (cyanopeptolin) and toxic 
(microcystin) peptides in a bloom of Microcystis sp. from a Chilean Lake. Syst. Appl. Microbiol., 23(2): 191-197.

Otsuka S., Suda S., Li R., Watanabe M., Oyaizu H., Matsumoto S., Watanabe M. M., 1999. Phylogenetic relationships between toxic and non-toxic strains of the genus Microcystis based on $16 \mathrm{~S}$ to $23 \mathrm{~S}$ internal transcribed spacer sequence. FEMS Microbiol. Lett., 172(1): 15-21.

Pham T. -L., Dao T. -S., Shimizu K., Lan-Chi D. -H., Utsumi M., 2015. Isolation and characterization of microcystin-producing cyanobacteria from Dau Tieng Reservoir, Vietnam. Nova Hedwigia, 101(1-2): 3-20.

Pham T. -L., Dao T. -S., Tran N. -D., Nimptsch J., Wiegand C., Motoo U., 2017. Influence of environmental factors on cyanobacterial biomass and microcystin concentration in the Dau Tieng Reservoir, a tropical eutrophic water body in Vietnam. Ann. Limnol. - Int. J. Lim., 53: 89-100.

Puddick J., Prinsep M., Wood S., Miles C., Rise F., Cary S., Hamilton D., Wilkins A., 2013. Structural characterization of new microcystins containing tryptophan and oxidized tryptophan residues. Marine Drugs, 11(8): 3025-3045.

Rinta-Kanto J. M., Wilhelm S. W., 2006. Diversity of microcystin-producing cyanobacteria in spatially isolated regions of Lake Erie. Appl. Environ. Microbiol., 72(7): 5083-5085.

Rouhiainen L., Vakkilainen T., Siemer B. L., Buikema W., Haselkorn R., Sivonen K., 2004. Genes coding for hepatotoxic heptapeptides (microcystins) in the cyanobacterium Anabaena strain 90. Appl. Environ. Microbiol., 70(2): 686-692.
Sivonen K., 1996. Cyanobacterial toxins and toxin production. Phycologia, 35(6S): $12-24$.

Tamura K., Peterson D., Peterson N., Stecher, G., Nei M., Kumar S., 2011. MEGA5: Molecular evolutionary genetics analysis using maximum likelihood, evolutionary distance, and maximum parsimony methods. Mol. Biol. Evol., 28(10): 2731-2739.

Tillett D., Dittmann E., Erhard M., von Dohren H., Borner T., Neilan B. A., 2000. Structural organization of microcystin biosynthesis in Microcystis aeruginosa PCC7806: an integrated peptidepolyketide synthetase system. Chem. Biol., 7(10): 753-764.

Urbach E., Robertson D. L., Chisholm S. W., 1992. Multiple evolutionary origins of prochlorophytes within the cyanobacterial radiation. Nature, 355(6357): 267-270.

Vaitomaa J., Rantala A., Halinen K., Rouhiainen L., Tallberg P., Mokelke L., Sivonen K., 2003. Quantitative real-time PCR for determination of microcystin synthetase e copy numbers for Microcystis and Anabaena in lakes. Appl. Environ. Microbiol., 69(12): 7289-7297.

Ye W., Liu X., Tan J., Li D., Yang H., 2009. Diversity and dynamics of microcystinProducing cyanobacteria in China's third largest lake, Lake Taihu. Harmful Algae, 8(5): 637-644.

Yoshida M., Yoshida T., Takashima Y., Hosoda N., Hiroishi S., 2007. Dynamics of microcystin-producing and nonmicrocystin-producing Microcystis populations is correlated with nitrate concentration in a Japanese lake. FEMS Microbiol. Lett., 266(1): 49-53. 